\title{
$\mathrm{X}$ linked severe mental retardation, craniofacial dysmorphology, epilepsy, ophthalmoplegia, and cerebellar atrophy in a large South African kindred is localised to Xq24-q27
}

Arnold L Christianson, Roger E Stevenson, C H van der Meyden, Julie Pelser, Francois W Theron, Petro L van Rensburg, Michael Chandler, Charles E Schwartz
Department of Human

Genetics and

Developmental

Biology, Faculty of

Medicine, University

of Pretoria, PO Box

2034, Pretoria 0001,

South Africa

A L Christianson

J Pelser

J C Self Research Institute of Human

Genetics, Greenwood

Genetic Center,

Greenwood, South

Carolina, USA

R E Stevenson

$M$ Chandler

C E Schwartz

Department of

Neurology, Faculty of Medicine, University of Pretoria, Pretoria, South Africa

$\mathrm{C} \mathrm{H}$ van der Meyden

Department of Anatomical Pathology, Faculty of Medicine, University of Pretoria, Pretoria, South Africa F Theron

Genetic Services Division, Gauteng Department of Health, Gauteng Provincial Government, Pretoria, South Africa

P L van Rensburg

Correspondence to: Professor Christianson.

Revised version received 15 June 1999

Accepted for publication 5 July 1999

\begin{abstract}
To date over $150 \mathrm{X}$ linked mental retardation (XLMR) conditions have been documented. We describe a five generation South African family with XLMR, comprising 16 affected males and 10 carrier females. The clinical features common to the 16 males included profound mental retardation $(100 \%)$, mutism despite apparently normal hearing $(100 \%)$, grand mal epilepsy $(87.5 \%)$, and limited life expectancy $(68.8 \%)$. Of the four affected males examined, all had mild craniofacial dysmorphology and three were noted to have bilateral ophthalmoplegia and truncal ataxia. Three of 10 obligate female carriers had mild mental retardation. Cerebellar and brain stem atrophy was shown by cranial imaging and postmortem examination. Linkage analysis shows the gene to be located between markers DXS424 (Xq24) and DXS548 (Xq27.3), with a maximum two point lod score of 3.10 .

(F Med Genet 1999;36:759-766)
\end{abstract}

Keywords: X linked mental retardation; epilepsy; cerebellar atrophy; ophthalmoplegia

An excess of males among the intellectually disabled was initially recognised by Penrose $^{1}$ when he studied a large cohort of institutionalised, mentally retarded subjects. In 1972 Lehrke $^{2}$ hypothesised that $\mathrm{X}$ linked genes would account for this male excess in mentally retarded populations. This predated by five years Sutherland's ${ }^{3}$ description of the tissue culture medium required to diagnose fragile $\mathrm{X}$ syndrome (FRAXA) chromosomally, an event which highlighted the significance of $\mathrm{X}$ linked mental retardation (XLMR) and kindled the search for XLMR genes.

Initially, documentation of XLMR conditions was slow, with Neri et $a l^{4}$ listing 39 in their review. The number of XLMR entities delineated has since increased several fold. ${ }^{56}$ In the most current update, 120 XLMR syndromes with more or less distinctive somatic, neuromuscular, behavioural, or metabolic manifestations are listed. ${ }^{6}$ Fifty-three of these syndromes have been mapped and 22 have been cloned. There are, in addition, 58 families with non-syndromic XLMR which have been mapped. Three genes that cause nonsyndromic XLMR have been cloned.

We report a large South African kindred with XLMR, associated with mild craniofacial dysmorphology, epilepsy, ophthalmoplegia, and cerebellar and brain stem atrophy. Linkage analysis places the gene between markers DXS424 (Xq24) and DXS548 (Xq27.3), with a lod score of 3.10 with no recombination. To the authors' knowledge, no similar XLMR condition has previously been reported.

\section{Family history}

This five generation, Afrikaans speaking, South African family (K8895) consists of 16 affected males and eight obligate carrier females (fig 1). The four living affected males (IV.5, V.3, V.4, and V.11) were examined clinically as were five of the six living obligate carrier females (III.1, III.4, IV.2, IV.8, and IV.14). Linkage studies have confirmed two additional female carriers. (IV.13 and V.5). Details of the clinical presentation of the remaining 12 affected males were obtained from their relatives. In addition, over the last 30 years various members of this family have been seen and investigated by different clinicians. Clinical details and investigation results from these previous consultations have been obtained and are reported.

\section{Case reports}

AFFECTED MALES

Patient V.3

Patient V. 3 was 24 years of age when examined. Pregnancy was normal, delivery was preterm, and birth weight was $1360 \mathrm{~g}$. Within the first year of life retarded milestones were noted and he developed tonic/clonic photosensitive grand mal seizures which were controlled on carbamazapine. He walked very clumsily on tiptoes by the age of 3 years, never spoke despite being considered able to hear, and never gained urinary or faecal continence or the ability to care for himself. He was operated on to correct a squint. His ability to walk was lost by the end of the first decade of life, and his intellect had been considered to have slowly regressed with age.

On examination he was profoundly mentally retarded and exhibited some autistic features. $\mathrm{He}$ was emaciated, weighing $32 \mathrm{~kg}$ (well below the 3 rd centile), and mildly microcephalic with an OFC of $51.6 \mathrm{~cm}$ (just below the $3 \mathrm{rd}$ centile).

Craniofacial features included a long, narrow face, a prominent, straight nose, a square, 


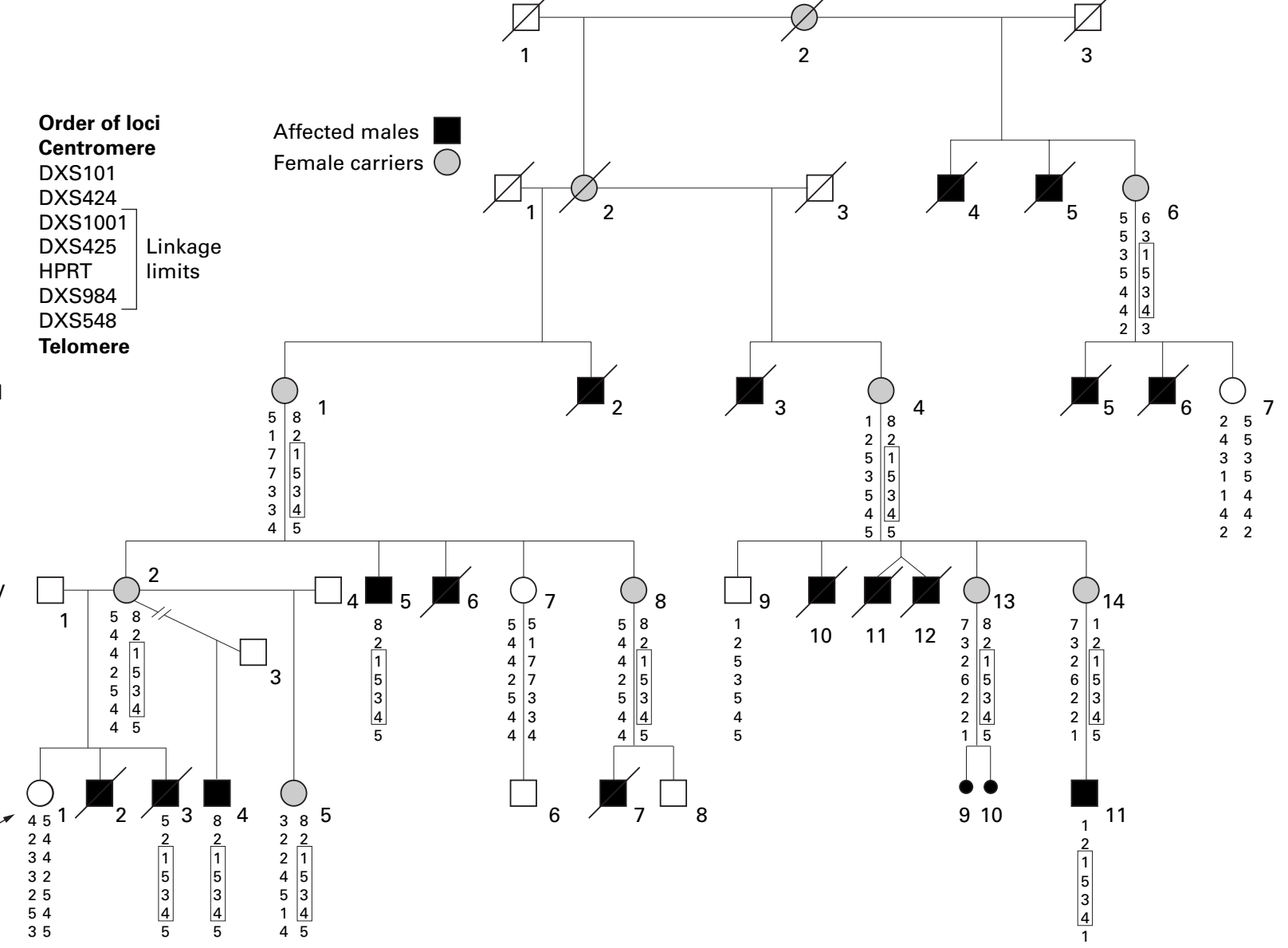

Figure 1 Partial pedigree of kindred 8255.

prognathic jaw, large ears, deep sunken eyes, and bushy eyebrows (fig 2). His chest was narrow, muscles in all limbs wasted, knees, elbows, and ankles contractured, and his fingers and toes were long and thin. Central nervous system (CNS) examination showed normal pupils, tone in all limbs was normal, and the reflexes in his arms were normal but were brisk at the knees. Plantar responses were equivocal. He had normal male genitalia with normal testicular volume.

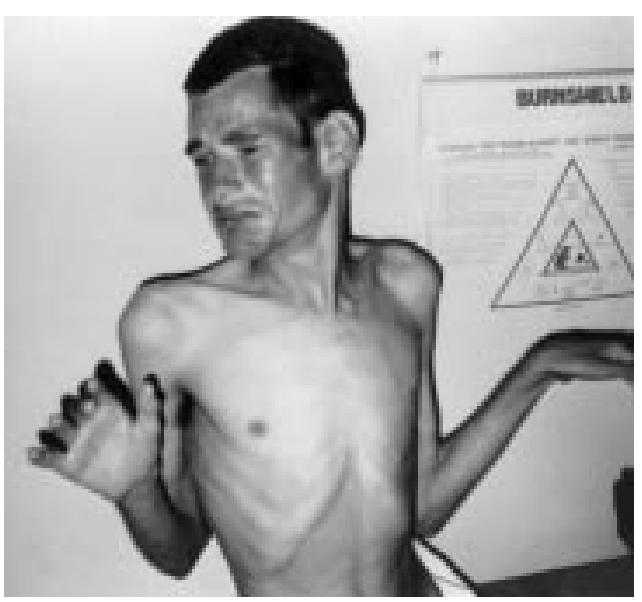

Figure 2 Patient V.3. Note long, narrow face, square, prognathic jaw, large ears, bushy eyebrows, and narrow chest.
Shortly after this examination he died of a confluent pyogenic bronchopneumonia superimposed on miliary tuberculosis. Neuropathological findings at necropsy included a brain mass which was below normal (1040 g). On gross examination, the cerebellum was atrophic, especially the vermis (fig 3). The brain stem was also atrophic. Widespread neuronal loss, sparing the dentate nucleus, was microscopically shown in the granular and Purkinje cell layers (fig 3). The molecular layer displayed microcystic change. Depletion of myelin was proved by Luxol stain. Loss of neurones was also found in the hippocampi, but no clear fallout of cortical or brain stem neurones could be discerned. No signs of active inflammation were found in the macroscopically opaque leptomeninges, although the arachnoid was focally fibrotic. Perforating midline arteries in the pons and some subarachnoid arteries were sclerotic.

Chromosomal $(46, \mathrm{XY})$ and DNA analysis for FRAXA were negative, and an amino acid screen and thyroid function tests were normal. An early EEG report recorded irregularities suggestive of epilepsy. A hearing assessment done at 5 years of age was considered within the normal range.

\section{Patient V.4}

The half brother of patient V.3, he was 20 years of age when examined. Born after a normal 

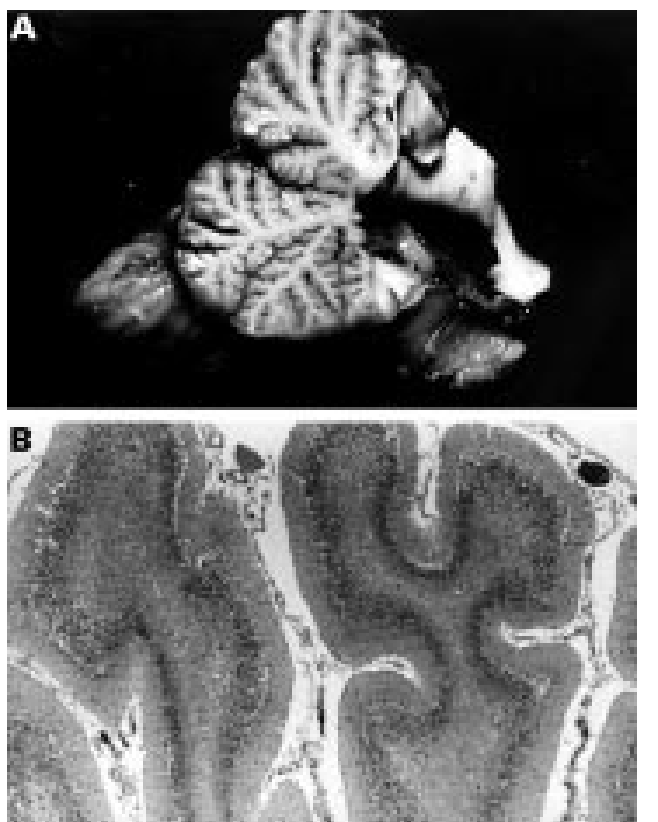

Figure 3 (A) Gross view of a median section of the cerebellum. Note the marked atrophy of the vermis and dilatation of the fourth ventricle. (B) Light microscopic view of the cerebellar folia. The molecular layer is thin and atrophic. Purkinje cells are totally absent and the granular layer is depleted ( $H \in \mathcal{E} E$ ).

pregnancy and a term vaginal delivery, and like his half brother (patient V.3), developmental delay and grand mal, photosensitive epilepsy presented in the first year of life. These seizures are at present controlled with carbamazapine. He never spoke, but was always considered able to hear, never gained continence, and walked late, but very clumsily. This ability was lost by the end of his first decade of life. He has also been considered to be slowly regressing with age.

He was profoundly retarded, emaciated (weight $30 \mathrm{~kg}$, well below the $3 \mathrm{rd}$ centile), OFC $52.5 \mathrm{~cm}$ (below the $3 \mathrm{rd}$ centile), and length $160 \mathrm{~cm}$ (3rd centile). Craniofacial features included a long, thin, expressionless face, large ears, a prominent, straight nose, square jaw, bushy eyebrows, and strabismus (fig 4). Decreased muscle bulk of all four limbs with flexion contractures of the knees and elbows were noted. He had adducted thumbs, long, thin fingers and toes, and single palmar creases on both hands. The penis and testicles were normal. The CNS showed normal pupillary reactions and fundoscopy and a truncal ataxia. A characteristic finding was an inability of the eyes (lateral recti muscles) to look laterally, at times associated with phasic nystagmoid jerks in the direction of gaze. Tone and reflexes were considered normal, his plantar reflexes were equivocal and ankle clonus was absent.

Chromosomal $(46, \mathrm{XY})$ and DNA analysis for FRAXA were negative, as were an organic and amino acid screen. Plasma lactate, uric acid and hexosaminidase $\mathrm{A}$ and $\mathrm{B}$ were normal. The cerebrospinal fluid had normal chemistry and no cells. The EEG exhibited a diffuse epileptiform dysfunction with left frontotemporal focal features and a mild degree of diffuse slowing. An MRI scan showed a prominent cisterna magna and enlarged fourth ventricle, cerebellopontine, and supracerebellar cisterna. The cerebellum, most notably the vermis, was small and atrophic. The prepontine cistern was enlarged and the pons appeared atrophic. The posterior fossa was diminished in size. The size of the lateral and third ventricles were normal. The conclusion was a picture of cerebellar and brain stem atrophy (fig 5).

\section{Patient IV.5}

He was the oldest, living, affected male ( 37 years). Pregnancy and delivery were normal. Delayed milestones were recognised by 7 months of age and grand mal seizures began in the first year of life and continue to the present, despite treatment with phenobarbitone. $\mathrm{He}$ never spoke or gained continence and has always been unable to care for himself. A history was obtained of a staggering, broad based gait at the age of 4 to 5 years, with an inability to walk unsupported since the age of 7 years. There has always been a question regarding his visual ability and mentally he is presently considered to be regressing with age.

$\mathrm{He}$ was profoundly mentally retarded, had some autistic features, was emaciated (weight $32 \mathrm{~kg}$, well below the $3 \mathrm{rd}$ centile), and his OFC was $52.8 \mathrm{~cm}$ (below the $3 \mathrm{rd}$ centile). Craniofacial features included a long, narrow, impassive face with a prognathic, square jaw, large ears $(7.5 \mathrm{~cm})$ with flattened upper pinnae, deep sunken eyes, convergent strabismus, bushy eyebrows, and a long, straight nose (fig 6). The musculature in all limbs was poorly developed, he had a narrow chest, pectus excavatum of the lower sternum, long fingers with stiff joints, adducted thumbs, and mild contractures at his knees. His genitalia, including testicular volume, were normal. CNS clinical features

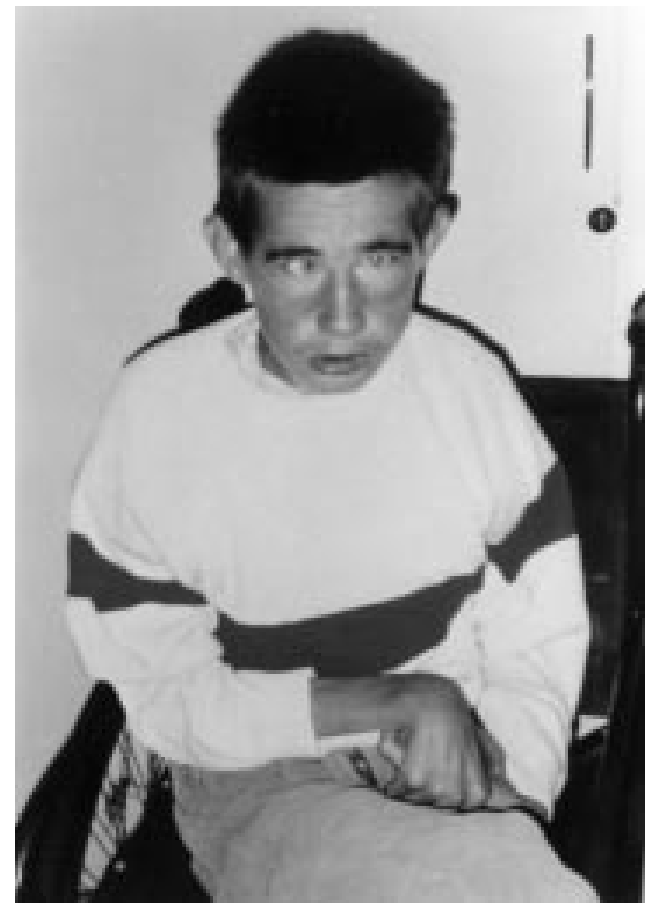

Figure 4 Patient V.4. Note long, narrow face, square jaw, strabismus, bushy eyebrows, prominent, straight nose, and large ears. 

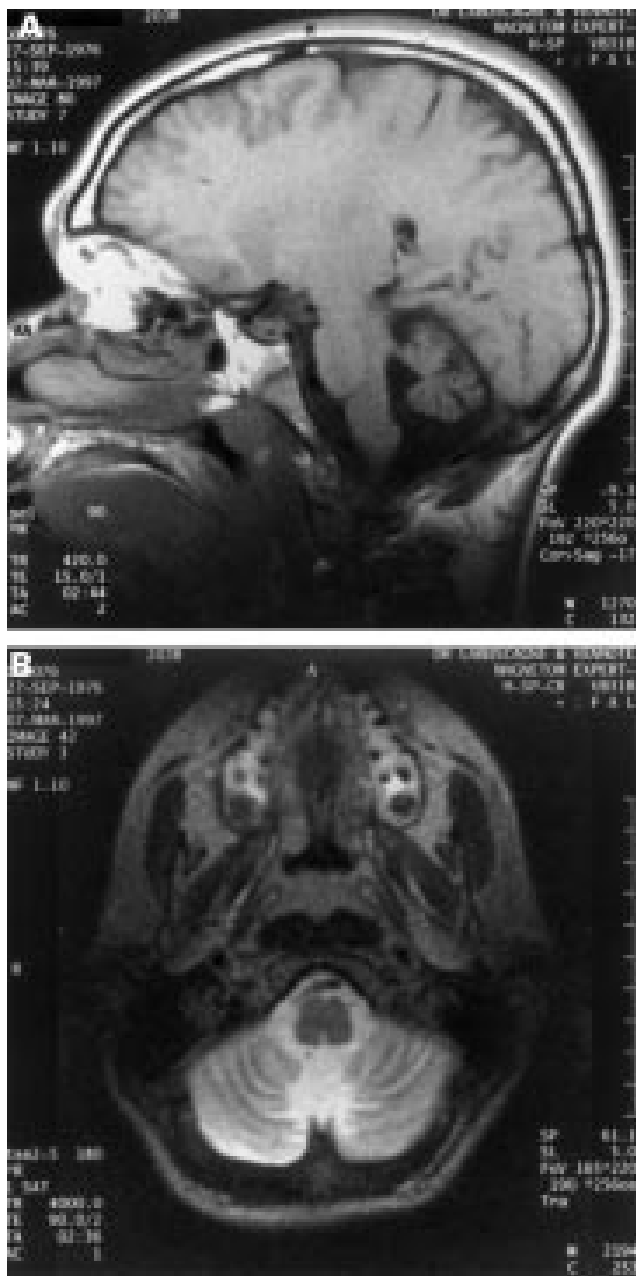

Figure 5 MRI scans of patient V.4 showing a prominent cisterna magna, enlarged fourth ventricle, and prominent cerebellopontine, prepontine, and supracerebellar cisterns, as well as a small, atrophic vermis and pontine atrophy. (A)

Sagittal view and (B) coronal view of the cerebellum.

included a cataract in the right eye, normal left pupil and fundus, an ophthalmoplegia equivalent to patient V.4, and truncal ataxia. Tone and reflexes were considered to be normal in all limbs, plantar reflexes equivocal, and no ankle clonus was present.

Chromosomal analysis $(46, \mathrm{XY})$ for FRAXA and a full metabolic screen for organic and amino acidopathies were negative and his uric acid level was normal.

Patient V.11

$\mathrm{He}$ is the youngest, living, affected male, aged 10 years. He was delivered vaginally after a normal pregnancy, birth weight 3600 g. Developmental delay was recognised by 6 months of age and grand mal tonic/clonic seizures began at approximately 1 year of age. At present he is on phenobarbitone, but he has also received phenytoin. He has never spoken or been continent, is spoon fed, and has never walked unassisted.

On examination, he was a friendly, approachable child, in contrast to the three previous patients. He was thin with a weight of 23.8 $\mathrm{kg}$ (above the $3 \mathrm{rd}$ centile), length $130 \mathrm{~cm}$ (10th centile), and OFC $51 \mathrm{~cm}$ (10th centile). His facial appearance was in keeping with the other affected family members in that he had a long, narrow face, square, prognathic jaw, large ears with flat upper pinnae (length $6.4 \mathrm{~cm}$ ), convergent strabismus, and sunken eyes (fig 7). A photograph of him, taken in infancy, indicates a normal looking child. His musculoskeletal system was remarkable in that he had joint laxity of his fingers, wrists, and ankles. The musculature in all limbs was poorly developed. His chest was narrow with widely spaced nipples and mild pectus excavatum at the lower sternum. Genitalia were prepubescent with a normal penis but small testicles, volumes between 1 and $2 \mathrm{cc}$. CNS examination showed normal pupils and fundi and an ophthalmoplegia equivalent to patients V.4 and IV.5. The muscle tone in all limbs was normal with normal reflexes at the knees and ankles, flexor plantar responses, and no clonus. He had trun-

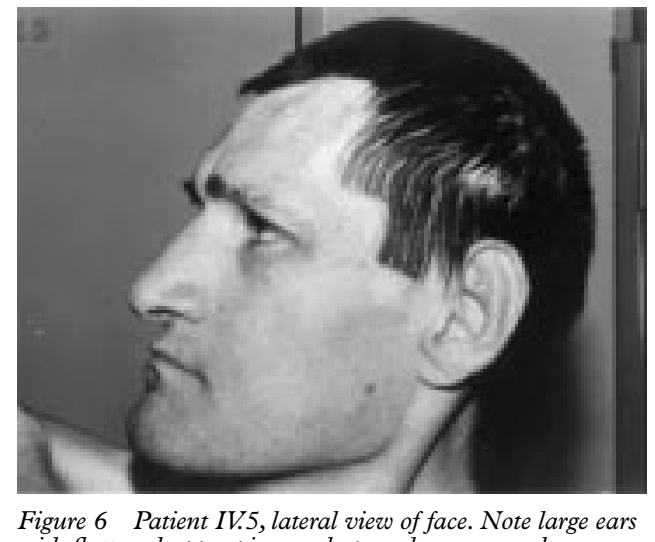

Figure 6 Patient IV.5, lateral view of face. Note large
with flattened upper pinnae, deep sunken eyes, and prominent, straight nose.

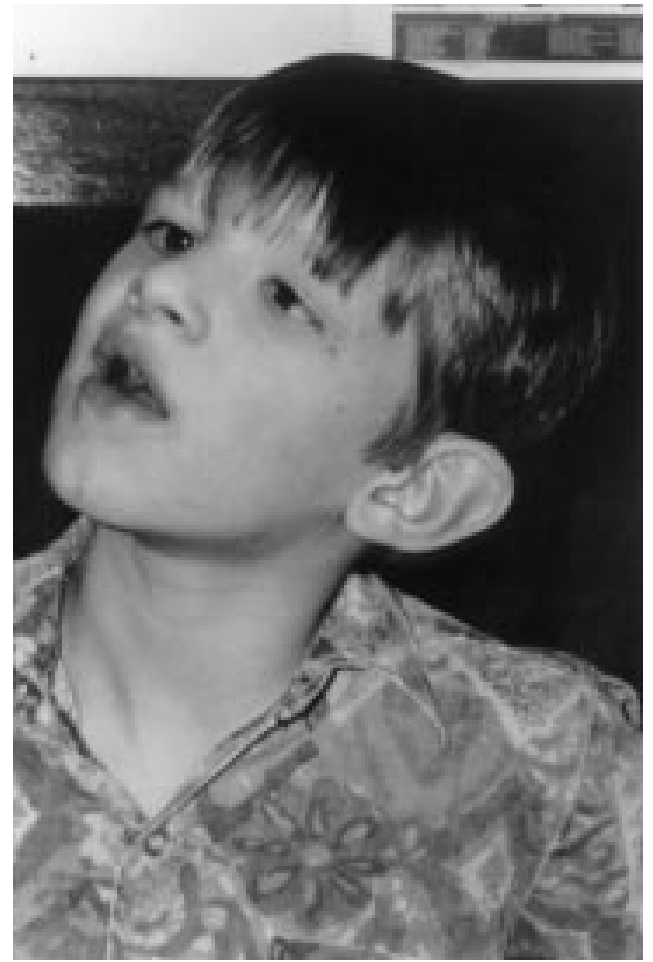

Figure 7 Patient V.11. Note large ears with flattened upper pinnae, square jaw, long straight, nose, and strabismus. 
Table 1 Clinical features of affected males in K8255

\begin{tabular}{|c|c|c|c|c|c|c|c|c|c|c|c|c|c|c|c|c|c|}
\hline \multirow[b]{2}{*}{ Clinical features } & \multicolumn{16}{|c|}{ Patients } & \multirow{2}{*}{$\begin{array}{l}\text { Total }(n=16) \\
\text { No }(\%)\end{array}$} \\
\hline & II. 4 & II. 5 & III. 2 & III. 3 & III. 5 & III. 6 & IV.5t & IV. 6 & IV.10 & IV.11 & IV.12 & $V .2$ & $V .3 t$ & $V .4 t$ & V.7 & V.11t & \\
\hline \multicolumn{18}{|l|}{ CNS features } \\
\hline Profound MR & + & + & + & + & + & + & + & + & + & + & + & + & + & + & + & + & $16 / 16(100)$ \\
\hline Microcephaly & NK & NK & NK & NK & NK & NK & + & NK & NK & NK & NK & NK & + & + & NK & - & $3 / 4(75)$ \\
\hline Mutism & + & + & + & + & + & + & + & + & + & + & + & + & + & + & + & + & $16 / 16(100)$ \\
\hline Incontinence & NK & NK & + & + & + & + & + & + & + & + & + & + & + & + & + & + & $14 / 14(100)$ \\
\hline Epilepsy & NK & NK & + & + & + & + & + & + & + & + & + & + & + & + & + & + & $14 / 14(100)$ \\
\hline Ophthalmoplegia & NK & NK & NK & NK & NK & NK & + & NK & NK & NK & NK & NK & NK & + & NK & + & $3 / 3(100)$ \\
\hline Squint & NK & NK & NK & NK & + & + & + & NK & NK & NK & NK & NK & + & + & NK & + & $6 / 6(100)$ \\
\hline Truncal ataxia & NK & NK & NK & NK & NK & NK & + & NK & $\mathrm{NK}$ & NK & NK & NK & NK & + & NK & + & $3 / 3(100)$ \\
\hline Non-ambulatory & - & + & - & - & - & + & - & - & - & + & + & + & - & - & + & + & $7 / 16(43.75)$ \\
\hline Late ambulation & + & - & + & + & + & - & + & + & + & - & - & - & + & + & - & - & $9 / 16(56.25)$ \\
\hline Adducted thumbs & + & + & NK & NK & + & + & - & NK & NK & NK & NK & NK & - & + & NK & - & $5 / 8(62.5)$ \\
\hline \multicolumn{18}{|l|}{ Craniofacial features } \\
\hline Long, narrow face & NK & NK & NK & NK & $+^{\star}$ & NK & + & NK & NK & NK & NK & NK & + & + & NK & + & $5 / 5(100)$ \\
\hline Large ears & NK & NK & NK & NK & $t^{\star}$ & NK & + & NK & NK & $+^{\star}$ & $+^{\star}$ & NK & + & + & NK & + & $7 / 7(100)$ \\
\hline Square, prognathic jaw & NK & NK & NK & NK & $+^{\star}$ & NK & + & NK & NK & NK & NK & NK & + & + & NK & + & $5 / 5(100)$ \\
\hline Long, aquiline nose & NK & NK & NK & NK & $+^{\star}$ & NK & + & NK & NK & NK & NK & NK & + & + & NK & + & $5 / 5(100)$ \\
\hline \multicolumn{18}{|l|}{ Muculoskeletal system } \\
\hline Decreased muscle bulk & NK & NK & NK & NK & $+^{\star}$ & NK & + & NK & NK & NK & NK & NK & + & + & NK & + & $5 / 5(100)$ \\
\hline Contractures & NK & NK & NK & NK & NK & NK & + & NK & NK & NK & + & NK & + & + & NK & - & $4 / 5(80)$ \\
\hline Long fingers/toes & NK & NK & NK & NK & $+^{\star}$ & NK & + & NK & NK & $+^{\star}$ & $+^{\star}$ & NK & + & + & NK & + & $7 / 7(100)$ \\
\hline Narrow chest & NK & NK & NK & NK & NK & NK & + & NK & NK & NK & NK & NK & + & + & NK & + & $4 / 4(100)$ \\
\hline Age of death (y) & NK & NK & 5 & 18 & 39 & $30+$ & A & 15 & 5 & 5 & 15 & 17 & 24 & A & 15 & A & \\
\hline
\end{tabular}

+Clinical feature present

*From photographs.

tPatients examined.

$\mathrm{A}=$ patients alive. $\mathrm{NK}=$ not known.

cal ataxia and walked with assistance with a broad based gait. On clinical testing he appeared to hear, responding appropriately to voices and sounds.

Chromosomal $(46, \mathrm{XY})$ and molecular analysis for FRAXA was negative; a full metabolic screen for organic acids, amino acids, and uric acid was normal. Plasma lactate and hexosaminidase A and B levels were normal. An EEG showed the presence of sharp transients and an excess of diffuse slow activity. The dominant background frequency was $4-7 \mathrm{~Hz}$. Cerebrospinal fluid chemistry, including lactate level, were normal and no cells were

Table 2 Two point lod scores for X chromosome loci $v$ XLMR condition

\begin{tabular}{|c|c|c|c|c|c|c|c|c|c|}
\hline \multirow[b]{2}{*}{ Locus } & \multirow[b]{2}{*}{ Location } & \multicolumn{6}{|c|}{ Recombination $(\theta)$} & \multirow[b]{2}{*}{$\theta \max$} & \multirow[b]{2}{*}{$Z \max$} \\
\hline & & 0.001 & 0.01 & 0.05 & 0.1 & 0.2 & 0.3 & & \\
\hline DXS996 & Xp22.32 & & & & & & & & \\
\hline KAL 5' & $\mathrm{Xp} 22.32$ & -8.67 & -4.69 & -2.01 & -0.97 & -0.14 & 0.14 & 0.36 & 1.70 \\
\hline DXS987 & $\mathrm{Xp} 22.31$ & -3.43 & -1.46 & -0.20 & 0.22 & 0.45 & 0.40 & 0.22 & 0.45 \\
\hline DXS7593 & $\mathrm{Xp} 22$ & -7.13 & -4.40 & -1.98 & -0.97 & -0.15 & 0.12 & 0.36 & 0.16 \\
\hline DXS989 & $\mathrm{Xp} 22.13$ & -3.22 & -1.24 & 0.03 & 0.45 & 0.63 & 0.51 & 0.20 & 0.64 \\
\hline DXS451 & Xp22.13 & & & & & & & & \\
\hline DXS992 & $\mathrm{Xp} 21.3$ & -6.83 & -3.84 & -1.78 & -0.96 & -0.26 & 0.01 & 0.39 & 0.07 \\
\hline DXS1110 & $\mathrm{Xp} 21.1$ & -3.71 & -1.73 & -0.41 & 0.06 & 0.37 & 0.38 & 0.25 & 0.40 \\
\hline DXS993 & Xp11.4 & & & & & & & & \\
\hline MAOA & $\mathrm{Xp} 11.4$ & -9.11 & -5.13 & -2.45 & -1.39 & -0.52 & -0.16 & 0.46 & 0.00 \\
\hline DXS1003 & Xp11.3 & -3.93 & -1.94 & -0.59 & -0.08 & 0.27 & 0.32 & 0.27 & 0.33 \\
\hline DXS255 & $\mathrm{Xp} 11.23$ & & & & & & & & \\
\hline DXS991 & Xp11.21 & 0.49 & 0.49 & 0.47 & 0.43 & 0.34 & 0.22 & 0.00 & 0.49 \\
\hline ARA & $\mathrm{Xq} 12$ & -5.51 & -2.54 & -0.58 & 0.13 & 0.58 & 0.59 & 0.25 & 0.62 \\
\hline DXS983 & $\mathrm{Xq} 12$ & & & & & & & & \\
\hline DXS566 & Xq13.3 & -9.90 & -6.72 & -3.70 & -2.29 & -0.99 & -0.38 & 0.50 & 0.00 \\
\hline DXS986 & $\mathrm{Xq} 21.1$ & -3.72 & -1.74 & -0.43 & 0.05 & 0.35 & 0.36 & 0.25 & 0.38 \\
\hline DXS995 & Xq21.1 & -1.64 & -0.66 & -0.04 & 0.15 & 0.23 & 0.20 & 0.21 & 0.23 \\
\hline DXS1002 & $\mathrm{Xq} 21.31$ & -6.55 & -3.56 & -1.52 & -0.71 & -0.04 & 0.18 & 0.35 & 0.20 \\
\hline DXS990 & $\mathrm{Xq} 21.33$ & -4.47 & -2.49 & -1.15 & -0.63 & -0.20 & -0.03 & 0.42 & 0.02 \\
\hline DXS101 & Xq22.1 & -10.51 & -7.02 & -4.08 & -2.69 & -1.31 & -0.60 & 0.57 & 0.00 \\
\hline DXS424 & $\mathrm{Xq} 23$ & -0.67 & 0.31 & 0.90 & 1.05 & 1.00 & 0.76 & 0.13 & 1.06 \\
\hline DXS1001 & Xq24 & 2.81 & 2.78 & 2.65 & 2.46 & 1.99 & 1.41 & 0.00 & 2.81 \\
\hline DXS425 & $\mathrm{Xq} 25$ & 2.50 & 2.48 & 2.37 & 2.20 & 1.78 & 1.26 & 0.00 & 2.50 \\
\hline HPRT & Xq26.1 & 1.83 & 1.81 & 1.70 & 1.55 & 1.21 & 0.84 & 0.00 & 1.83 \\
\hline DXS984 & Xq27.1 & 1.65 & 1.62 & 1.50 & 1.34 & 1.02 & 0.68 & 0.00 & 1.65 \\
\hline DXS548 & Xq27.3 & -1.10 & -0.12 & 0.49 & 0.66 & 0.67 & 0.51 & 0.15 & 0.69 \\
\hline DXS1113 & Xq28 & -0.39 & 0.58 & 1.13 & 1.24 & 1.10 & 0.77 & 0.11 & 1.24 \\
\hline DXS8011 & $\mathrm{Xq} 28$ & -2.79 & -0.82 & 0.42 & 0.82 & 0.95 & 0.76 & 0.18 & 0.96 \\
\hline DXS8103 & $\mathrm{Xq} 28$ & -0.34 & 0.62 & 1.14 & 1.21 & 1.04 & 0.74 & 0.10 & 1.21 \\
\hline p39 & $\mathrm{Xq} 28$ & -3.99 & -2.00 & -0.68 & -0.19 & 0.16 & 0.21 & 0.28 & 2.12 \\
\hline DXS1108 & $\mathrm{Xq} 28$ & 2.34 & 2.30 & 2.12 & 1.90 & 1.42 & 0.94 & 0.00 & 2.35 \\
\hline
\end{tabular}

present. His EMG and nerve conduction studies were considered to be within normal limits.

Patients V.2, V.7, IV.6, IV.10, IV.11, IV.12, III.2, III. 3, III.5, III. 6, II. 4, and II.5

The clinical features of these affected males are documented in table 1 .

\section{FEMALE CARRIERS}

There were eight obligate female carriers in the family, of whom six (I.2, II.2, II.6, III.1, III.4, and IV.8) were considered mentally and physically normal. Two mothers (IV.2 and IV.14) were mildly affected. These two women (IV.2 and IV.14) had behavioural problems and were aggressive as adolescents and children. Patient IV.2 had school learning difficulties and patient IV.14 was considered mildly mentally retarded. Of the two female carriers confirmed by the linkage studies, one (V.5) was noted to have had learning difficulties at school.

\section{Methods}

Genomic DNA was isolated from peripheral blood by high salt precipitation. ${ }^{7}$ Purified DNA was diluted to a concentration of $105 \mu \mathrm{g} / \mathrm{ml}$ and stored at $4^{\circ} \mathrm{C}$ in TE $(10 \mathrm{mmol} / 1$ Tris- $\mathrm{HCl}$, pH 7.6, 1 mmol/1 EDTA).

For microsatellite analysis, specific dinucleotide or trinucleotide polymorphisms were generated as given in Nelson et $a l^{8}$ or as available through the Genome DataBase. The forward primers were synthesised and labelled with fluorescein amidite (FluorePrime, Pharmacia) using a Beckman Oligo 1000 DNA synthesiser and desalted through sephadex G-25 (NAP-10 columns, Pharmacia). The polymorphisms generated were detected by an Automated Laser Fluorescent Sequencer (ALF, Pharmacia) using Fragment Manager.

Two point disease to marker analysis was conducted by means of the program MLINK of the linkage package. ${ }^{9}$ The mutation rate and 


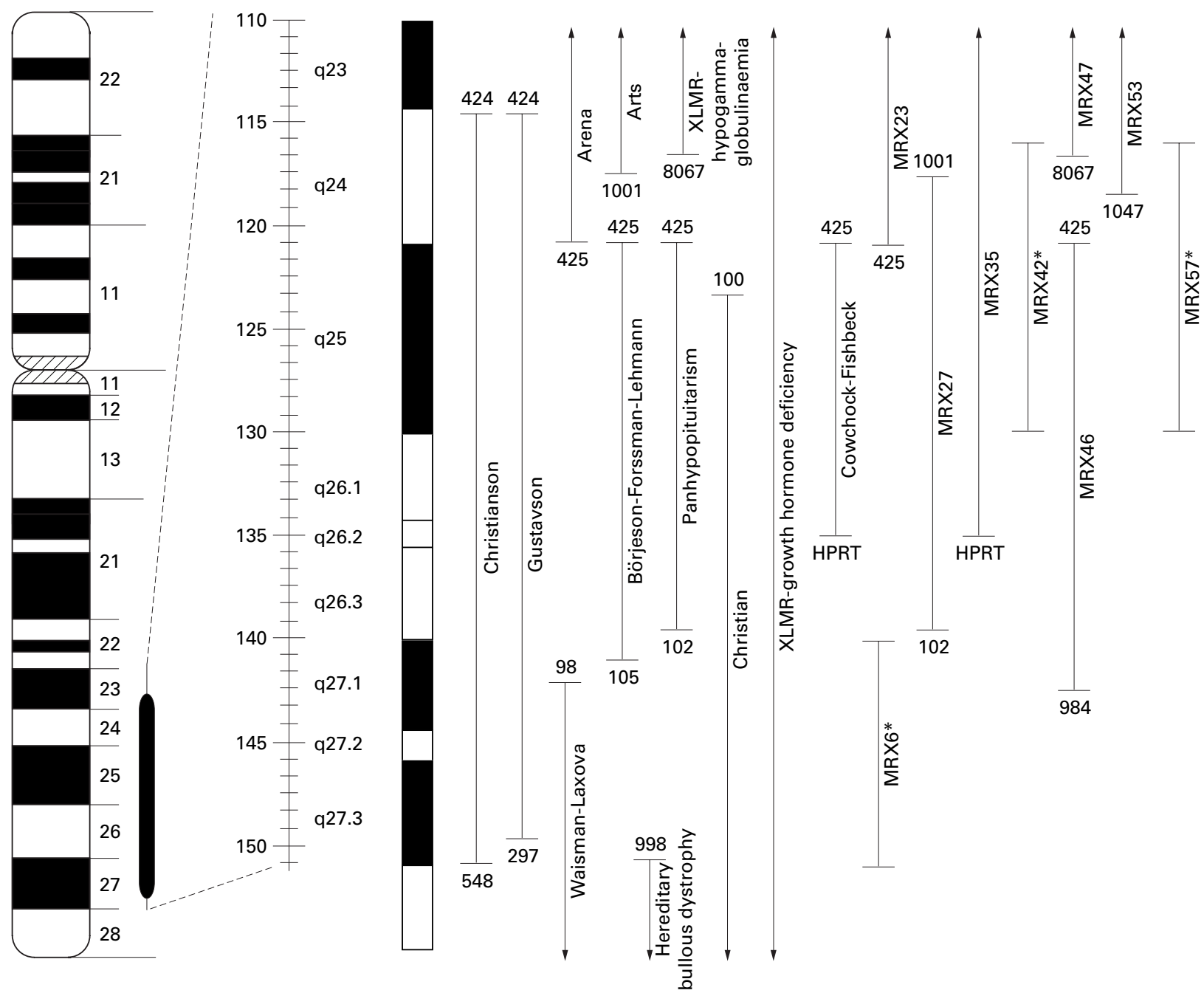

Figure 8 Idiogram of the X chromosome showing mapping limits of XLMR syndromic and non-syndromic XLMR families linked to markers in Xq24-q27. The asterisk after an MRX number indicates that the localisation limits have not been published. The numbers indicated at the ends of the linkage limits are DXS marker numbers.

gene frequency were set at $3 \times 10^{-6}$ and 0.0001 , respectively. Penetrance was set at $100 \%$ for males and at $25 \%$ for females. The latter penetrance figure was based on the observation that two of the eight obligate carriers had mild mental retardation (fig 1 ).

$\mathrm{X}$ inactivation analysis of the women in K8895 was done using the polymorphism at the androgen receptor (AR) locus in Xq12 as previously described. ${ }^{10}{ }^{11}$

\section{Results}

LINKAGE

Linkage analysis of family K8895, using microsatellite markers distributed along the length of the $\mathrm{X}$ chromosome, initially detected linkage to locus DXS1001 in Xq24 (table 2). A lod score of 3.10 with no recombination was observed at this locus. In order to refine the localisation, additional markers were used. Four loci (DXS1001, DXS425, HPRT, and DXS984) exhibited tight linkage (zero recombination) at various lod scores (table 2). The region of localisation could be defined by recombination at the proximal locus DXS424 (Xq24) and the distal locus DXS548 (Xq27.3) (table 2, fig 8).
X INACTIVATION

Obligate carriers as well as other females in K8895 were studied for their X inactivation status. Using the degree of methylation at the $\mathrm{AR}$ locus as a measure of $\mathrm{X}$ inactivation of a particular X, no evidence was found for selective inactivation. This was true for both the obligate carriers as well as the women who did not carry the "at risk" X chromosome (fig 1).

\section{Discussion}

A male preponderance in mentally retarded populations has long been recognised and it is now accepted that this is at least in part a consequence of XLMR genes. ${ }^{12}$ Less widely known is that if the contribution of XLMR genes is analysed with respect to the level of mental retardation, this contribution is greatest in the mild to moderate mental retardation range (IQ 36-70), as compared to the severe and profound range (IQ 0-35). Indeed the relatively late recognition of the contribution of XLMR genes to the prevalence of mental retardation could in part be attributed to surveys initially being confined to institutions whose occupants are more severely intellectually handicapped, rather than community 
based studies in which mild/moderate mentally retarded subjects would be ascertained. ${ }^{11}{ }^{12}$

The clinical picture presented by the affected males in this family (table 1), who were all institutionalised, was one of apparent normality at birth, which occurred after a normal pregnancy. Thereafter, within the first year of life and often by 6 months of age, developmental delay was recognised, followed by the onset of grand mal seizures by the end of the first year of life. The epilepsy was photosensitive in three of eight affected males. Neurodevelopment proceeded very slowly initially with only some patients eventually attaining the ability to walk unaided by the age of 3 years. Speech, continence, and the ability to care for themselves in the most basic manner was never attained. A developmental plateau was reached in the second half of the first decade and thereafter a slow regression is observed in those who survive into and beyond the second decade of life. Common clinical features derived from the four surviving males examined included mild craniofacial dysmorphology, similar musculoskeletal findings, and neurological signs comprising truncal ataxia, convergent strabismus, and an ophthalmoplegia. These CNS features were considered compatible with the neuropathological features documented in patient V.3 and the MRI picture of patient V.4.

Linkage to Xq24-q27 places the XLMR syndrome described here in one of the least densely mapped regions of the $\mathrm{X}$ chromosome. However, both syndromic and non-syndromic forms of XLMR have overlapping mapping limits (fig 8). Among the XLMR syndromes mapped to Xq24-q27, Arena syndrome has the most similar phenotype. ${ }^{14}$ Both entities have absent speech, absence or loss of ambulation, incontinence, truncal ataxia, contractures, and hypoplasia or atrophy of the cerebellum and brain stem. In Arena syndrome, the facial appearance is not distinctive, seizures were described in only one patient, and MRI shows changes in the basal ganglia suggesting iron deposit. Heterozygote manifestations were not recognised. The overall findings are sufficiently similar in the two syndromes to suggest allelism. Another candidate for allelism, Gustavson syndrome, has overlapping linkage limits, cerebellar hypoplasia, microcephaly, short stature, profound developmental failure, blindness, deafness, and seizures. Severe impairments are obvious from birth and death occurs in infancy or early childhood. ${ }^{15}$

Other XLMR syndromes with overlapping mapping limits include Arts, BörjesonForssman-Lehmann, Christian, WaismanLaxova, XLMR-hypogammaglobulinaemia, XLMR-isolated growth hormone deficiency, and XLMR-panhypopituitarism syndromes, none of which is similar in phenotype to the syndrome described here..$^{6-19}$ Schimke syndrome, as yet not mapped, shares some manifestations, including microcephaly, profound mental retardation, absent speech, short stature, generalised asthenia, secondary contractures, hypoplastic cerebellum, and ophthalmoplegia. ${ }^{20}$
Ten non-syndromic XLMR families, designated MRX6, 23, 27, 30, 35, 42, 46, 47, 53, and 57, map to Xq24-q27. ${ }^{6}$ It would be premature to exclude the genes responsible for their condition since mutations in different domains of a gene might produce quite different phenotypic consequences.

Also within the linkage interval, three genes that cause XLMR have been cloned. These are HPRT (Lesch-Nyhan syndrome), ${ }^{21}$ OCRL1 (Lowe syndrome), ${ }^{22}$ and GPC3 (SimpsonGolabi-Behmel syndrome).$^{23}$ Of the three syndromes, Lesch-Nyhan is most similar clinically but can be excluded by the normal uric acid studies in patients IV.5, V.4, and V.11. Lowe syndrome is excluded by the absence of amino aciduria and progressive renal failure in all the patients examined. Simpson-Golabi-Behmel is an overgrowth syndrome quite different from the entity described here.

In conclusion, we have presented a family with an X linked mental retardation syndrome, in which the causative gene is located in Xq24q27. Affected males have mild craniofacial dysmorphology, ophthalmoplegia, atrophy of the cerebellum and brain stem, and seizures. Some carrier females have had learning and behavioural problems. Further delineation of this gene and the genes for other XLMR syndromes also having linkage in this region will be required before these conditions can be further differentiated.

We would like to thank the patients and their mothers for their time and forbearance, Professor L Dreyer of the Department of Anatomical Pathology for her advice and photographic skills, Sister C W Bredenkamp, Department of Health, Mpumalanga, who referred the patients, Mrs S Swarts for her care and attention to detail when producing the manuscript, and Dr B Häne and M May for laboratory assistance and advice. This work was supported in part by grant HD 26202 (CES).

1 Penrose LS. A clinical and genetic study of 1280 cases of mental defect (The Colchester Survey). London: Medical Research Council Special Report Series, 1938:No 229.

2 Lehrke RG. A theory of X-linkage of major intellectual Lehrke RG. A theory of X-linkage of
traits. Am $\dot{\mathcal{F}}$ Ment Defic 1972;76:611-19.

3 Sutherland GR. Fragile sites on human chromosomes: Sutherland GR. Fragile sites on human chromosomes:
demonstration of their dependence on the type of tissue demonstration of their dependence on
culture medium. Science 1977;197:265-6.

4 Neri G, Gurrieri F, Gal A, Lubs HA. XLMR genes: update 1990. Am f Med Genet 1991;38:186-9.

5 Lubs HA, Chiurazzi P, Arena JF, Schwartz C, Tranebjaerg L, Neri G. XLMR genes: update 1996. Am f Med Genet 1996;64:147-57.

6 Lubs H, Chiurazzi P, Arena J, Schwartz C, Tranebjaerg L, Neri G. XLMR genes: updated 1998. Am ₹ Med Genet (in press).

7 Schwartz CE, Ulmer J, Brown A, Pancoast I, Goodman HO, Stevenson RE. Allan-Herndon syndrome II. Linkage to DNA markers in Xq21. Am f Hum Genet 1990;47:454-8.

8 Nelson DL, Ballabio A, Cremers F, Monaco AP, Schlessinger D. Report of the Sixth International Workshop on X 307-42.

9 Lathrop GM, Lalouel JM, White RL. Construction of human genetic linkage maps: likelihood calculations for human genetic linkage maps: likelihood calculation
multilocus analysis. Genet Epidemiol 1986;3:39-52.

10 Allen RC, Zoghbi HY, Moseley AB, Rosenblatt HM, Belmont JW. Methylation of HpaII and HhaI sites near the polymorphic CAG repeat in the human androgen-receptor gene correlates with $\mathrm{X}$ chromosome inactivation. F Hum Genet 1992;51:1229-39.

11 Pegoraro E, Schimke RN, Arahata K, et al. Detection of new paternal dystrophin gene mutations in isolated cases of dystrophinopathy in females. Am $\mathcal{F}$ Hum Genet 1994;54: 989-1003.

12 Turner G, Collins E, Turner B. Recurrence risk of metal retardation in sibs. Med f Aust 1971;1:1165-6.

3 Glass IA. X linked mental retardation. F Med Genet 1991;28:361-71

14 Arena JF, Schwartz C, Stevenson R, et al. Spastic paraplegia with iron deposits in the basal ganglia: a new X-linked mental retardation syndrome. Am f Med Genet 1992;43: mental

15 Gustavson KH, Anenerén G, Malmgren H, Dahl N, Ljunggren CG, Backman H. New X-linked syndrome with severe 
mental retardation, severely impaired vision, severe hearing defect, epileptic seizures, spasticity, restricted joint mobility and early death. Am F Med Genet 1993;45:654-8.

16 Kremer H, Hamel BCJ, van den Helm B, et al. Localization of the gene (or genes) for a syndrome with X-linked mental retardation, ataxia, weakness, hearing impairment, loss of vision and a fatal course in early childhood. Hum Genet 1996;98:513-17.

17 Hamel BCJ, Smits APT, Otten BJ, van den Helm B, Ropers $\mathrm{HH}$, Mariman ECM. Familial X linked mental retardation and isolated growth hormone deficiency - clinical and molecular findings. Am f Med Genet 1996;64:35-41.

18 Gedeon AK, Kozman HM, Robinson H, et al. Refinement of the background genetic map of Xq26-q27 and gene localisation for Börjeson-Forssman-Lehman syndrome. Am F Med Genet 1996;64:63-8.

19 Ropers HH, Hulsebos TJM, Menko FH, van Oost BA, Lungarotti MS, Arwerf F. The gene for hereditary bullous dystrophy, X linked macular type, maps to the Xq27.3-qter region. Am f Med Genet 1995;55:1096-100.

Theron I. A new $\mathrm{X}$-linked syndrome comprising progressive basal ganglion dysfunction, mental and growth retardation, external ophthalmoplegia, postnatal microcephaly and deafness. Am $\mathcal{F}$ Med Genet 1984;17:323-32.

21 Jolly DJ, Okayama $\mathrm{H}$, Berg $\mathrm{P}$, et al. Isolation and characterization of a full-length expressible cDNA for human hypoxanthine phosphoribosyltransferase. Proc Natl Acad Sci USA 1983;80:477-81.

22 Silver DN, Lewis RA, Nussbaum RL. Mapping the Lowe oculocerebrorenal syndrome to Xq24-q26 by use of restriction fragment length polymorphisms. $\mathcal{f}$ Clin Invest 1987;79:282-5.

23 Pilia G, Hughes-Benzie RM, MacKenzie A, et al. Mutations in GPC3, a glypican gene, cause the Simpson-
Golobi-Behmel overgrowth syndrome. Nat Genet 1996;12: 241-7. 